\title{
A MORTE COMO CATEGORIA FILOSÓFICA: FINITUDE E DETERMINAÇÃO EM FEUERBACH
}

\author{
Antônio José Lopes Alves ${ }^{1}$
}

\section{Resumo:}

Este artigo tem por tema uma parte do projeto de pesquisa Revisão Crítico-Materialista da Bioética, que compreende entre seus objetivos rastrear na tradição filosófica materialista momentos nos quais certos conceitos chave para a reflexão, a elaboração e o discurso bioéticos foram em alguma medida abordados ou problematizados. Neste trabalho se analisa o caráter propriamente filosófico da mortalidade no pensamento de Feuerbach. Delimita-se o papel constitutivo que a reflexão acerca da morte desempenha na sua elaboração antropológica. Em especial se examinará Pensamentos sobre morte e imortalidade, conjunto de textos publicado anonimamente em 1830. Aqui a morte aparece possuindo uma função específica de demarcação do ser concreto dos homens de maneira oposta àquela observada na religiosidade cristã arrimada na noção de imortalidade individual. Teologicamente, a essência humana é posta numa fictícia realidade situada para-além da concretude natural. Neste sentido, a excelência humana somente poderia ser atualizada porquanto a alma tenha negada a sua circunscrição pelo sensível e carnal. Feuerbach, ao contrário, pretende ancorar a dignidade humana de modo assertivo, como afirmação de um estar-aí objetivamente existente, na exata medida em que assume a mortalidade como delimitação positiva do indivíduo em sua conexão com o gênero, que continua e assimila a pessoalidade finita na sua virtual infinitude. O reconhecimento de teor positivo da mortalidade individual põe em marcha uma reelaboração da compreensão das determinações antropológicas do indivíduo, baseada no reconhecimento daquele liame essencial, uma vez que apenas na comunidade fundada no gênero, no compartilhamento de uma essência natural comum com os semelhantes, obtêm os indivíduos a possibilidade de afirmação de suas qualidades. A compreensão deste caráter imediatamente finito da existência dos homens descortina diretamente a possibilidade da reflexão acerca de outros elementos, tais como a determinação particular da pessoa enquanto esta pessoa, a real significação da temporalidade como construção de uma história específica da vivência, e não como mera passagem abstrata do tempo, entre outros complexos temáticos.

Palavras-Chave:Feuerbach, Mortalidade, Finitude, Generidade, Determinação Particular.

\begin{abstract}
:
This article is subject part of the research project Critical Review-Materialist Bioethics, which includes among its objectives trace the philosophical tradition materialistic times in which certain key concepts for reflection, the preparation and the bioethical discourse were addressed in some measure or made problems. This paper analyzes the properly philosophical character of mortality at the thought of Feuerbach. Delimits to the constitutive role that thinking about death plays in its anthropological development. In particular it will examine Thoughts about death and immortality, set of texts published anonymously in 1830. Here, the death appears having a specific function demarcation of concrete being of men in the opposite way to that observed in the Christian religiosity sustained in individual immortality notion. Theologically, the human essence is set in a fictional reality set for beyond the natural concrete. In this sense, human excellence could only be updated because the soul has denied his constituency by sensitive and carnal. Feuerbach, in contrast, aims to anchor the human dignity of assertive way, as an affirmation of a being-there objectively existing in the exact extent that assumes mortality as a positive delimitation of the individual in its connection to the genre, which continues and assimilates personhood finite in its virtual infinity. Recognition of positive content of individual mortality sets in motion a reworking of understanding of anthropological determinations of the individual, based on the recognition that essential bond, since only the community founded on gender, the sharing of a common natural essence with similar gain individuals the opportunity to claim their qualities. Understanding this immediately finite nature of existence of men directly opens up the possibility of reflection on other elements such as the particular determination of the person while that person, the real significance of temporality as building a specific history of experience, and not as mere Abstract passage of time, among other thematic complex.
\end{abstract}

\footnotetext{
${ }^{1}$ Professor COLTEC-UFMG. Doutor em Filosofia UNICAMP. Membro do Grupo de Pesquisa Marxologia: Filosofia e Estudos Confluentes CNPq. Editor de Verinotio - Revista de Filosofia e Ciências Humanas COLTEC-UFMG/CNPq.
} 
Key words: Feuerbach, Mortality, Finiteness, Generic Character, Particular Determination.

Este artigo se refere a uma parte do projeto de pesquisa Revisão Crítico-Materialista da Bioética, que compreende entre seus objetivos rastrear na tradição filosófica materialista momentos nos quais certos conceitos chave para a reflexão, a elaboração e o discurso bioéticos foram em alguma medida abordados ou problematizados. $\mathrm{O}$ esforço de pesquisa da história da filosofia tem por principal escopo reelaborar sob a perspectiva do materialismo, em particular aquele consignado no pensamento marxiana, as categorias centrais que definem o terreno das discussões bioéticas. Por conseguinte, conceitos como os de vida, vida humana, pessoa, respeito, finitude, entre outros, são objeto de reflexão crítica que intenta num duplo movimento determinar seus pressupostos e reconfigurá-los a partir de outras bases. Neste trabalho, em especial, se analisa o caráter propriamente filosófico da mortalidade no pensamento de Feuerbach.

Neste diapasão, o pensamento feuerbachiano é aqui examinado não como um objeto totalmente autônomo ou autolegitimado, em um esforço erudito de pesquisa ou meramente diletante ou ainda como proposta monográfica. Este caráter da abordagem se dá então num duplo registro. Primeiramente, a elaboração do pensador alemão se inscreve na tentativa de esquadrinhar num momento de importante inflexão da tradição filosófica do iluminismo alemão, como a mortalidade aparece em sua tessitura de categoria. Assim, a mortalidade ultrapassa o terreno imediato da reflexão provocada no nível da cotidianidade do sujeito, para desvelar-se em seu potencial propriamente filosófico categorial. Deste modo, interessará sobretudo elevar a percepção cognitiva da morte à alçada da elaboração teórica, no curso da qual, pretende-se mostrá-lo, a discussão de Feuerbach indica, conquanto sem uma explicitação completa, a série de conexões entre a mortalidade e a determinação do ser em geral, do ser vivo e do ser humano genérico consciente. Pensar com rigor a mortalidade do sujeito humano concreto natural é pois, no afastamento de fantasias como a imortalidade da alma individual, pontuar as características de ente enquanto ente e delimitar a existência humana como generidade. Em segundo lugar, a abordagem de Feuerbach aqui exposta está na dependência da identificação em seu pensamento de determinados elementos que categorialmente são observáveis na atualidade no interior dos debates, das reflexões e dos discursos bioéticos.

\begin{tabular}{|c|c|c|c|c|}
\hline Qenista Dialectus & Ano 2 & n. 6 & Janeiro - Agosto 2015 & p. $107-123$ \\
\hline
\end{tabular}


A relação indivíduo x gênero que se flagrará nos termos feuerbachianos como transposta e traduzida religiosa e teologicamente como persistência de uma suposta substância incorpórea é o centro em torno dos quais gira, às vezes em falso, a teorização acerca dos dilemas e decisões do terreno da bioética. Esta confrontação necessária entre duas dimensões ou polos do ser social - como o refere Lukács em sua Para uma ontologia do ser social - se expressa no cotidiano na forma duma incongruência possível, ou efetiva, do comportamento ético frente aos valores. Na maioria das vezes o desencontro tem o caráter de uma limitação do agir individual em virtude da fixidez dos padrões da generidade, onde o posicionamento ético dos sujeitos se choca com determinada normatização - a qual implica uma normalização - das relações sociais. O do agir propriamente ético confronta, por vezes de modo dramático, as diversas expressões positivas do gênero e é adstringido por estas. Em outras circunstâncias, pode passar-se mesmo oposto, situações nas quais as potências genéricas da vida humana, a virtualidade do encontro eu e tu ou ainda dos diversos eus com aquele eu que é um nós, encontra da parte dos indivíduos em seus laços cotidianos e/ou pragmáticos uma resistência passiva como que afirmação da inércia própria a uma dada forma de individuação. Num caso, a forma da individualidade pode estar, por assim dizer, "além" das estruturas definidas pela vigência do gênero. Num outro, ocorre que o patamar possivelmente mais avançado não é galgado pelos indivíduos, ou quando se o é trata-se de uma operacionalização meramente pragmática que nunca supera o âmbito da reprodução dos mesmos modos de vida.

Por conseguinte, entender as determinações que presidem e perfazem a conexão complexa e complicada entre individualidade e generidade, um dos pilares, senão talvez até o pilar central, do, e no, pensamento de Feuerbach, revela-se como demanda importante para a elaboração de uma bioética a partir da perspectiva do materialismo. Na medida em que a bioética, como conjunto de experiências sociais, afirma-se como necessidade reflexiva e legiferante na particularidade dos problemas da intervenção científico-tecnológica sobre os viventes, é de suma importância capturar teoricamente os lineamentos principais a partir dos quais se engendram as categorias que delimitam este campo particular dos controversos. No que tange à bioética como um modus filosófico reflexivo particular, o tema da finitude do sujeito e da infinitude relativa do gênero se desvela como uma das matrizes da filosofar sobre o tema da bioética.

\begin{tabular}{|c|c|c|c|c|}
\hline QRonista Dialectus & Ano 2 & n. 6 & Janeiro - Agosto 2015 & p. $107-123$ \\
\hline
\end{tabular}


Uma vez consignado o caráter da empreitada, é mister delimitar igualmente o objeto de exame textual. Tomar-se-á aqui principalmentePensamentos sobre a morte $e$ imortalidade(GedankenüberdenTodundUnsterblichkeit), publicado anonimamente em 1830. Esta obra consta de quatro partes principais - O sentido ético da morte; $O$ especulativo ou o fundamento metafísico da morte; $O$ espiritual ou o fundamento psicológico da morte e $A$ nulidade(Nichtigkeit) da morte e imortalidade - precedidos por uma Introdução e um Prefácio do Editor (da lavra do próprio Feuerbach, sob a falsa alcunha) rematado por uma Conclusão e, curiosamente, por Poemas e Sátiras sobre o sentido da finitude temporal. Escrito que inicialmente poderia valer a entrada na vida acadêmico-institucional alemã, mas que, quando da revelação de sua autoria e significação, a vedou-lhe para sempre ao acesso da vida intelectual oficial. O tema é a finitude radical do homem individual concreto, seu limite existencial e ontológico. Como objeto do texto, no qual a categoria do particular ganhar relevo, ironicamente serviu para na sua expressão como matéria da teoria, limitar o espaço de ação do pensador e determinar-lhe a essência e as feições que ganharia sua obra. Para sempre um outsider, na recusa da forma adstringente mediante a qual o mundo se organizava, Feuerbach com este texto percebe como tarefa a proposição de um futuro ainda sem lastro certo.No que toca ao escrito como totalidade de sentidos em si, aqui a morte aparece possuindo uma função específica de demarcação do ser concreto dos homens de maneira oposta àquela observada na religiosidade cristã arrimada na noção de imortalidade individual. Teologicamente, a essência humana é posta numa fictícia realidade situada para-além da concretude natural. Neste sentido, a excelência humana somente poderia ser atualizada porquanto a alma tenha negada a sua circunscrição pelo sensível e carnal. Feuerbach, ao contrário, pretende ancorar a dignidade humana de modo assertivo, como afirmação de um estar-aí objetivamente existente, na exata medida em que assume a mortalidade como delimitação positiva do indivíduo em sua conexão com o gênero, que continua e assimila a pessoalidade finita na sua virtual infinitude.

O reconhecimento de teor positivo da mortalidade individual põe em marcha uma reelaboração da compreensão das determinações antropológicas do indivíduo, baseada no reconhecimento daquele liame essencial, uma vez que apenas na comunidade fundada no gênero, no compartilhamento de uma essência natural comum com os semelhantes, obtêm os indivíduos a possibilidade de afirmação de suas qualidades. A compreensão deste caráter imediatamente finito da existência dos homens descortina diretamente a possibilidade da reflexão acerca de outros elementos, tais como a determinação particular da pessoa enquanto

\begin{tabular}{|l|l|l|l|l|}
\hline Q Ponista Dialectus & Ano 2 & n. 6 & Janeiro - Agosto 2015 & p. 107-123 \\
\hline
\end{tabular}


esta pessoa, a real significação da temporalidade como construção de uma história específica da vivência, e não como mera passagem abstrata do tempo, entre outros complexos temáticos. A determinação essencial da finitude em Feuerbach tem uma importante conexão com a crítica da religião em geral, em especial o cristianismo, porquanto tenha a ideia de uma infinitude individual concreta se tornado um dos pilares da mediação entre a teologia estrito senso e a promesse de bonheur que como comunidade religiosa aquele precisa acenar. Neste sentido, a imortalidade da alma dos indivíduos seria uma participação na infinitude necessária e atual de deus. Por conseguinte, teologicamente,

(...) não há nada em Deus que não haja na personalidade finita; a mesma coisa, o mesmo conteúdo que há em Deus há no homem; do mesmo modo que aqueles que afirmavam que não havia nada no intelecto que antes não houvera estado nos sentidos, estabeleciam uma simples diferença formalentre o conteúdo espiritual e o conteúdo sensível, assim também de maneira idêntica, há entre Deus e o homem somente uma diferença formal, uma diferença, que unicamente consiste no grau, no quantum; as mesmas determinações há tanto em Deus quanto no homem, apenas que naquele são infinitas, e neste finitas, isto é, que naquele estão realizadas em um grau infinitamente mais alto (...) (FEUERBACH, 1960, p. 23).

No âmbito circunscrito desta participação distributiva, pois que se afirma na pressuposição de um compartilhamento desigual das mesmas características essenciais, a morte como tal pode ser tomada como momento de mera inflexão, onde se estabelece apenas uma negação externa que advém à individualidade como um acidente devido à corporeidade de sua existência irreal. Na morte, a alma do indivíduo seria, concebida na forma do seu ser verdadeiro. A mortalidade é um atributo essencial à materialidade natural, mas puramente exterior à individualidade. Tem-se assim uma negação da finitude no seio mesmo da efetividade do sujeito na medida em que seu o estar aqui e agora determinado e situado, o qual contempla como possibilidade inerente o não estar mais, é declarado inessencial. A mortalidade mesma não possui densidade existencial e espessura categorial, não faz parte pois das determinações fundamentais, essenciais, ideais de caráter definidor. Este arrimo teológico apresenta consequências importantes também para a vivência terrenal do indivíduo, uma delas de natureza extremamente negativa para a autoconsciência:

(...) como deveria e poderia o indivíduo pensar sobre e em seu fim, dado que ele mesmo somente dentro do infinito se pensa, já que em Deus mesmo não encontra o fim de si mesmo e o princípio de sua morte, senão o princípio de sua existência, de sua realidade pessoal, posto que para ele Deus é somente o

\begin{tabular}{|l|l|l|l|l|}
\hline Q Ponista 2 ialectus & Ano 2 & n. 6 & Janeiro - Agosto 2015 & p. 107-123 \\
\hline
\end{tabular}


começo de sua finitude, e não ao mesmo tempo o fim de sua finitude? (FEUERBACH, 1960, p. 24).

Em outros termos, conquanto seja mortal enquanto corpo e natureza, mas o seja na admissão de uma exterioridade com relação a isto, o indivíduo vê na sua continuidade com deus, a permanência de si como infinitude. Origem e término não são pois congruentes e nem tem um remetimento recíproco. A fonte da qual dimana a efetividade finita nega apenas o caráter finito provisório de ser natureza, na exata proporção em que acolhe a substância como alma imortal, infinita. Por conseguinte,"Como poderia o indivíduo mirar na profundidade da morte, se ele próprio no mais profundo somente vê a superfície e a brilhante parte externa que o reproduz e reflete a si mesmo?"(FEUERBACH, 1960, p. 24). A determinação finita não pertence ao indivíduo como delimitação de seu ser verdadeiro, logo, a finitude de seu Dasein aparece como uma parte meramente externa, manifestação, de sua verdade. É interessante notar como a participação no ato de existência puro da divindade, mediado temporalmente por ser natureza, abre as vias para uma séria de inconsistências ontológicas. Incoerência do ser posto pelo infinito com uma vivência individual finita que deverá ser negada para a sobrevivência de uma substância infinita apartada de qualquer delimitação pela morte do corpo.

Neste sentido, ser ou estar natureza, abre um hiato entre o ato puro infinito donde emana e a finitude temporal emanada, entre a essência real e a existência fenomênica do indivíduo. Uma contradição existencial que o dar-se como natureza do infinito coloca a individualidade como uma figuração tensa e dilacerada entre sua determinação primeira e última, sua consonância pressuposta com o divino, e o seu existir como um feixe de atributos determinados, uma dada e irredutível finitude dada, como aquilo que o homem não é em essência, seu não-ser, o que o circunscreve como entidade discreta e (de)limitada; a determinação finita é pura adstrição, uma negação de todas as demais possibilidades do ato puro de ser. Na junção contraditória é posto uma quimera desconcertante, sem par, sem lugar, ambivalente na natureza, terceiro entre a plenitude e a limitação:

A combinação do ser e do não-ser, faz surgir um terceiro, que não é um puro ser, mas que tampouco é um não-ser. Não é que o homem não seja nada, mas tampouco é absolutamente ser, senão que é esta determinada essência ou algo essência. Em consequência, o não-ser não deixa de causar que algo seja como o ser(FEUERBACH, 1993, p. 102).

\begin{tabular}{|l|l|l|l|l|}
\hline Q Ponista Qialectus & Ano 2 & n. 6 & Janeiro - Agosto 2015 & p. 107-123 \\
\hline
\end{tabular}


Em outros termos, Feuerbach localiza criticamente na sua aproximação lógica para com a concepção religiosa e conceitual subjacente à tese da imortalidade da alma individual, o problema central da determinação particular como ponto essencial do ser concreto. Traduzido pela tradição teológica como pura afirmação da negação, o ser determinado terá reconhecida na argumentação do filósofo sua dignidade categorial. Nesta passagem, aparece a determinação como o remate que permite ao particular concreto ao menos uma analogia com o ser. Entre a pretensa posição absoluta de um pleno ato de ser e a particularidade como negação, Feuerbach pretende sustentar a determinação particular como delimitação de um ser frente aos demais. Anos mais tarde dirá que o ser só existe junto daquilo que é, ou seja, ser é um caráter de concretude e finitude localizável apenas na remissão necessária a modos específicos, finitos, de ser. O ser infinito só existe em virtude de suas interações de um todo com seus partícipes genéricos. O gênero é infinito, mas somente pode ser, e sê-lo, como gênero natural dos entes que são. O Dasein determinado aparece ele também como ato, não puro por certo, não como convivência imediata de um todo vazio, mas como existência concreta dada.

Deus cumpre aqui antes uma função lógica na medida em que propicia por sua definição como universalidade a demarcação do efetivo, do experiencial, como forma particular por excelência. Utilizando o recurso da determinação pela negação do ser universal, Feuerbach pretende analisar e expor o conjunto das determinidades do homem individual concreto. Assim, o limite se transtorna num positivo, porquanto não mais se remeta ao não-ser pleno, mas a um modo real, natural, de ser. De certo modo, tem-se aqui uma inversão da consagrada fórmula spinoziana segundo a qual ominideterminatio est negatio numa elaboração positiva onde omnis negatio est determinatio. A pluralidade dos atributos naturais da individualidade humana pode emergir, na sua existência de figura particularizada, na proporção em que se estabelece a finitude como caráter determinativo do humano em sua efetividade, como nomos de seu ser real. A natureza discreta da existência não é apenas um dado sentido, mas vivido na pletora de contatos e pulsões suscitados pelo ser da individualidade frente ao conjunto das coisas. A diferença existencial emerge como determinação recíproca da finitude verdadeira de homem e de mundo. O ser relacional de maneira recíproca, delimitação mútua mediada pelo estar-aíde um modo objetivamente sensível. A corporeidade natural, com a série das diferenças relativas por esta sensivelmente atestada, é alçada ao patamar de determinação categorial. Por conseguinte,

\begin{tabular}{|l|l|l|l|l|}
\hline Q Ponista Qialectus & Ano 2 & n. 6 & Janeiro - Agosto 2015 & p. 107-123 \\
\hline
\end{tabular}


As coisas e seres, que existem fora de ti, que tu diferencias de ti, e que reconheces como não idênticas com teu eu e com tua mesmidade, e as quais ordena sob a ideia de gênero do objeto ou da natureza, são todos estes pontos de fronteira, de negação de ti mesmo; no mesmo grau e medida, em que existem as demais coisas fora de ti, neste mesmo grau e medida tu não és, e tantas como estes sejam, tantos pontos de determinação e fronteira tens tu e teu ser; em qualquer árvore, em qualquer parede, em qualquer mesa com que tropeces, tropeças ao mesmo tempo com tua morte, com o limite e o término de sua existência (FEUERBACH, 1960, p. 27).

Em que pese as indistinções ontológicas entre Gegenstand e Objekt, concretude por si e esta já na forma da intuição, por um lado, e, entre ente natural e ente posto pela atividade material dos homens, por outro, afora a acepção da atividade do indivíduo existente como receptividade passiva, fatos que serão criticamente examinados por Marx nas já clássicas $A d$ Feuerbach, há que ressaltar destarte como algo filosoficamente produtivo a assimilação da existência limítrofe recíproca dos entes como algo mais que um dada da certeza sensível. $\mathrm{O}$ finito é um ser limitado e um limitar-se pelas afecções suscitadas pelo que me fere os sentidos da carne. Além disso, a referência ao caráter de gênero, atribuível pelo indivíduo realmente e atualmente existente à mundaneidade que o toca e o pró-voca, dará azo à captação da generidade natural, material, física, como a única e verdadeira universalidade concreta que racionalmente se pode reconhecer. Uma vez situado o humano como finitude individual, a alma como a série das afecções existenciais do qual este finito determinado é percipiente, o gênero humano em que se subsumem os homens efetivos aparecerá como a verdadeira universalidade humana, que compreende e supera infinitude relativa, porque natural, a finitude necessária de cada homem.

Uma acepção do finito, portanto, que ultrapassa a convencional e teológica identidade com o mortal, como o voltar ao pó, a qual reaparecerá também ulteriormente na tradição, por exemplo, no pensamento sartreano. Não por acaso, na sua crítica à concepção heideggariana da finitude como idêntica à mortalidade. Entendida esta última pelo "Pastor do Ser" como um limite existencial imanente, como uma pausa ontológica, um arremate definidor do sentido e da lógica do existente. Sartre arrimado na sua determinação do Dasein como liberdade reivindica pois a escolha, um ato finito, situado, como existência efetiva e em sendo o vir a morrer uma negação direta desta virtualidade ativa, intenta superar a identidade imediata entre ser finito e ser mortal. A liberdade é sempre particularidade vivida, circunscrita, numa situação, frente à opacidade do que se encontra definido e dado. Neste diapasão, o que delineia a finitude não é a negatividade temporal, e sim, num nível ontológico primário, o

\begin{tabular}{|l|l|l|l|l|}
\hline Gevista Dialectus & Ano 2 & n. 6 & Janeiro - Agosto 2015 & p. 107-123 \\
\hline
\end{tabular}


estar sendo sempre uma liberdade. Sendo discreto, contornado, localizado, distinguível, não existir como todas, mas somente sendo esta-aqui constitui a natureza do ser finito. Daí Sartre poderá ousadamente afirmar que:

(...) a realidade humana continuaria sendo finita, ainda que fosse imortal, porque se faz finita ao escolher-se humana. Ser finito, com efeito, é escolherse, ou seja, anunciar a si mesmo aquilo que se é projetando-se rumo a um possível, com exclusão dos outros. Portanto, o próprio ato de liberdade é assunção e criação da finitude. Se eu me faço, faço-me finito e, por esse fato, minha vida é única. Conseqüentemente, mesmo se eu fosse imortal, me seria vedado "ter minha segunda chance"; é a irreversibilidade da temporalidade que me impede isso, e esta irreversibilidade nada é senão o caráter próprio de uma liberdade que se temporaliza (SARTRE, 2000, p. 669).

Aproveitando como mote o final da formulação do pensador francês acima reproduzida, abre-se então a via de ressaltar um outro aspecto decisivo de talhe filosófico que emerge no curso da discussão feuerbachiana em tela. De certo modo, a argumentação acerca da mortalidade irredutível do particular situado, ultrapassa potencialmente os quadros de uma discussão somente antropológica. $\mathrm{O}$ debate atinge o sentido de um exame especificamente categorial porquanto remeta a duas categorias centrais e mais gerais para o entendimento doente enquanto ente: tempo e espaço. Remissão esta que se aparta do "continente" dominante na filosofia, cuja geografia e topologia se assentam na concepção kantiana, para afirmar a vigência da temporalidade e da espacialidade como caráter objetivo da relação sensível e afectiva com o mundo. A transitividade de negação e afirmação, típica do hegelianismo, serve como instrumento de expressão da delimitação do caráter particular e, por isso, definido do ser dos homens como finitude concreta:

(...) espaço e tempo são, em primeiro lugar, afirmações de teu ser, mas ao mesmo tempo são também negações tuas. Tu és só no espaço e no tempo, começas no espaço e no tempo, mas também acabas neles; como indivíduo, não podes ser fora do espaço e do tempo, e portanto és só nesta vida. E, em segundo lugar, como ser existente em espaço e tempo, és um ser espacial e temporalmente limitado, ou antes um ser determinado pelo tempo e determinado pelo espaço, e nesta unidade de espacialidade e temporalidade és um ser animado e vivente, isto é um indivíduo vivo; corpo e alma em unidade constituem tua vida, teu ser é só ser vivo, mas precisamente porque vives, também morres, o que é tua afirmação é também tua negação (FEUERBACH, 1960, p. 64).

A radicalidade da afirmação da individualidade humana concreta pela via da negação da fantasia de sua persistência como entidade incorporal, num para além do mundo natural, põe

\begin{tabular}{|c|c|c|c|c|}
\hline QRevista Dialectus & Ano 2 & n. 6 & Janeiro - Agosto 2015 & p. $107-123$ \\
\hline
\end{tabular}


como resultante necessária a determinação da pessoalidade finita, principalmente no sentido anteriormente aludido com Sartre, como o acento essencial. Espaço e tempo, não obstante como espacialidade e temporalidade do vivido, não como formas físicas, são afirmadas na compreensão como momentos da objetividade do sujeito. Como formas de ser da concretude, não são postas em vigência pela experiência sensível abstratamente tomada - como o admite, no máximo, Kant - e sim põe-se como determinações efetivas da experiência real. Esta delimitação não se esgota, evidentemente nessa figuração genérica, mas, como é possível entrever, põe-se como uma escala de ser, de determinações que se aditam e se adensam. Do ser objetivo, natural, material em geral ao vivo, o discurso feuerbachino pede resolução na referência necessária ao patamar seguinte da naturalidade: o humano. Assim, "tu não és somente espacial, temporal e vivo, senão que és também ser consciente e espiritual [geistigesWesen], homem,"(FEUERBACH, 1960, p. 64). Assim, espírito e consciência como apanágios essenciais da individualidade humana revelam-se como traços constitutivos da naturalidade dos homens. Uma vez que, "A proposição: Eu sou um indivíduo determinado, tem portanto a sua expressão e sentido determinados apenas na proposição: Eu sou senciente. [Ich bin Empfindendes]"(FEUERBACH, 1960, p. 31). A determinação do indivíduo como finitude concreta é antes de tudo matéria de sua sensibilidade, de sua capacidade de ser tocado e de suas afecções reais. A efetividade das coisas, e não uma autoconsciência espiritual autônoma a priori, constitui a possibilidade de demarcação primeira e mais essencial do indivíduo como si mesmo.

É na relação com o que me nega, como as demais coisas que não sou, é que obtenho a posição de minha efetividade como ente natural, concreto, objetivo. O que, de uma parte, significa o remetimento obrigatório do caráter de sujeito à esfera do vivido, mas, de outra parte, igualmente, como formas naturais genéricas, devidas à atribuição distributiva ao gênero natural, à espécie. Assim o assevera Feuerbach que "Tua essência, como indivíduo, é evidentemente o gênero, tua essência como homem, como pessoa, é por conseguinte, a humanidade; o gênero, a humanidade, é por conseguinte objeto para ti, ao diferenciar-te tu de tua essência" (FEUERBACH, 1960, p. 67).Observa-se assim o nascedouro do que Marx denominará de gênero mudo, pois que se relaciona ao fato do abarcamento dos indivíduos sob o gênero como uma operação da natureza, numa dupla acepção. Da natureza das coisas e das coisas da natureza. Identificam-se deste modo, gênero real e definição conceitual, o que faz da naturalidade o parâmetro último do juízo das particularidades humanas, como particularidades naturais os afetos, forças e pulsões são expressões existencialmente

\begin{tabular}{|c|c|c|c|c|}
\hline Gevista Dialectus & Ano 2 & n. 6 & Janeiro - Agosto 2015 & p. $107-123$ \\
\hline
\end{tabular}


individualizadas de uma essência do gênero; da mesma maneira que a alma individual era uma imago Dei. Isto não obstante seja possível aos indivíduos, como uma determinação naturalmente dada, que estes se apartem de sua essência, a tomem por objeto de seus afetos e consciência, no sentimento religioso. Nota bene, o sentimento religioso dimana de uma capacidade delimitada pelo pertencimento imediato ao gênero, ainda que possa tomar uma forma estranhada, existir às consciências prática e teórica como um ente autônomo, ao lado e acima de homens e humanidade.

No entanto, o que importa, sobretudo é destacar o modo como este desenvolvimento retórico-analítico de Feuerbach redunda num entendimento da categoria que delimita o indivíduo em remissão e reciprocidade aos semelhantes. Na afirmação da relação necessária entre pessoalidade e finitude a individualidade concreta evidencia-se como referência para o discernimento das categorias.

Tu és indivíduo e pessoa determinada certamente como aquilo de que és consciente para ti, como o indivíduo determinado, que é objeto de tua consciência, mas não como pensante consciente, talvez como quem pensa algo determinado, mas não imediatamente como pensador (...)(FEUERBACH, 1960, p. 65-66).

O exame da pessoalidade fantástica do puro ser, deus, permite ao filósofo revelar por contraste que apenas a consciência humana, delimitada, finita, pode expressar a pessoa efetiva. Não na forma de uma suposta pessoa universal, o que seria uma contradição nos termos, mas sempre esta pessoa, determinada, como finitude humana e pessoal. Discussão do caráter da mortalidade como assinalação negada da finitude que não termina num elogio da morte ou na sua transformação em determinação existencial. Muito ao contrário, inscrevendose numa dada perspectiva materialista, que pode ser encontrada por exemplo em Montaigne, em seu De como filosofar é aprender a morrer, Feuerbach declara a partir do exame da natureza do finito humano, mediado pela lógica hegeliana, que

O que nega a existência mesma, não tem ele mesmo existência nenhuma, pois, ao negar-se a existência mesma, nega aquilo no qual, do qual e pelo qual, poderia existir; a morte, portanto, ao negar-se a si mesma como negação da existência, ao não ser nada na aniquilação do positivo, da vida mesma, é por isso a afirmação mesma da existência, a mais infalível e forte segurança e confirmação da absoluta realidade da existência e da vida (FEUERBACH, 1960, p. 84).

\begin{tabular}{|c|c|c|c|c|}
\hline QRonista Dialectus & Ano 2 & n. 6 & Janeiro - Agosto 2015 & p. $107-123$ \\
\hline
\end{tabular}


A morte conquanto não seja uma exterioridade ôntica ao ente vivo, não é por isso uma determinação ontológica do vivente. Neste sentido, o vir-a-ser-mortal na contingência radical posta pela temporalidade capturada pela analítica feuerbachiana, não redunda na afirmação da centralidade da morte, mas antes na delimitação de sua ausência de conteúdo determinado. Assim, a morte nunca é minha morte, nem é a mortalidade uma definição positiva de meu Dasein, não é minha destinação, porquanto seja a negatividade indeterminada, vazia, falta de determinidade, de qualidade; mera negação daquilo pelo qual as particularidades podem vir a ser algo, da existência concreta. Pois,

A negação da vida, que é a única coisa que a morte é, não é nenhuma negação vital nem real da vida. Por conseguinte, o fim do indivíduo, posto que não é para ele mesmo, tampouco tem nenhuma realidade para ele, pois para o indivíduos somente tem realidade o que é objeto de sua sensação, o que é para ele (FEUERBACH, 1960, p. 85).

Ecoando igualmente o epicurismo, Feuerbach declara na sequência que o sujeito deixa de ser para outro, não para ele mesmo; a morte é somente morte para os que vivem, não para os que morrem; para estes só existe a morte, e só é esta terrível, precisamente quando todavia não é morte. Na morte a dor é pois para os outros e somente para eles, na medida em que vivem podem experimentar na negação de meu ser a morte como virtualidade. A morte só é uma experiência como mortalidade, como visão experimentável por via analógica para os quais a morte não é ainda de modo algum no momento. Porquanto seja a faculdade vital do experienciar das vivências, dos carecimentos e das pulsões, e, no caso humano, a consciência viva de ser, o parâmetro reflexivo central, a aniquilação de qualquer possibilidade afectiva equivale em verdade a não-ser por definição. Toda e qualquer sensação, relação empírica ou afecção possui, neste diapasão mais valor que quaisquer suposições de imortalidade, porquanto sejam afirmações reais de existência de um existente de fato. A imortalidade abstratamente posta pela teologia, presunçosamente elevada a conhecimento, nada põe, não gera nenhum movimento, nem engendra ideia alguma.

\section{III}

O que se exprime conceitualmente como compreensão da finitude considerada em seu liame com o sentimento de pertença ao gênero desenvolver-se-átreze anos depois como uma analítica da origem antropológica da alienação religiosa. Este alienar-se compreendido agora como pressentimento irrefletido do gênero. A este respeito, não necessariamente haveria nada

\begin{tabular}{|l|l|l|l|l|}
\hline Q Povista Dialectus & Ano 2 & n. 6 & Janeiro - Agosto 2015 & p. 107-123 \\
\hline
\end{tabular}


de errado no sentimento religioso, pois este faria parte de uma pretensa 'natureza humana' imutável: "Na religião, o homem tem como coisa concreta (Gegenstand) a sua própria essência, sem saber que ela é a sua; a sua própria essência é para ele coisa como 'uma essência outra'". Assim sendo, o grande problema emerge quando este assume a forma de uma exteriorização na qual se estranham os afetos genéricos humanos como "religião". Nesse sentido, o complicador da religião é ser esta, "(...) a consciência de si, inconsciente [unbewußte], do homem" (FEUERBACH, 1841, p. 37). Ou seja, é uma Entfremdung em se opera uma divisão interna no homem, "(...) é a 'cisão' [Entzweinung] do homem consigo: ele põe Deus face a si como um ser que lhe é 'oposto' [entgegengesetzt]. Deus 'não' é o que o homem é - o homem 'não' é o que Deus é" (FEUERBACH, 1841, p. 37).O sentimento religioso convertido na forma da religião seria o elogio à essência universal do homem - ser de afetividade e carecimento - feito de maneira invertida:

(...) "o conteúdo e coisa concreta" [Gegesntand] da religião é inteiramente humano, e humano no duplo sentido deste termo, que significa tanto algo de positivo como de negativo; (...) a religião afirma incondicionalmente, não apenas os poderes da essência humana, mas também as fraquezas, os desejos mais subjetivos do coração humano, como é o caso dos milagres; (...) o "segredo" [Geheims] "da teologia" é a "antropologia", o segredo do espírito absoluto o chamado espírito finito e subjetivo. Mas a religião não tem consciência do caráter humano de seu conteúdo; pelo contrário, opõe-se ao que é humano, ou pelo menos 'não confessa' que o seu conteúdo é humano (FEUERBACH, 1841, p. 369).

Isso equivaleria a colocar a sede de suas forças e de seu cerne pulsional, inclusive no que tange aos carecimentos e às incompletudes, bem quanto ao sofrimento irredutível daí originados para além de seu ser natural. Tais aspectos, considerados naturais pelo iluminismo em geral - constituintes e manifestações da menschlicheWesen- como dados, são postos religiosamente de modo ideal, fora do homem, por meio de uma projeção. Nesse sentido, Deus é a alienação da natureza humana, do amor, da paixão, da razão e dos afetos. Nos deuses, os homens se contemplam como exterioridade. O conjunto de suas energias essenciais, de seus atributos irrevogáveis, de sua existência como ente, passaria a existir, a tomar forma em uma figura exterior e independente deles. É preciso, então, retirar tal alienação do espírito e, encarando a própria naturalidade dos afetos, caberia realizá-los por meio da mediação do político e da convivência comunal, de modo real no mundo dos homens. Esse seria "o ponto de viragem necessário da história" [Der notwendigeWendepunkt der Geschichte] (Cf. FEUERBACH, 1841, p. 369). Portanto, como o afeto é natural, o sentimento

\begin{tabular}{|l|l|l|l|l|}
\hline Q Ponista Dialectus & Ano 2 & n. 6 & Janeiro - Agosto 2015 & p. 107-123 \\
\hline
\end{tabular}


de pertença ao gênero que torna possível os próprios afetos, malversados religiosamente, também o seria.

A irmandade humana, por conseguinte, seria um fato natural não reconhecido conscientemente e, por conseguinte, distorcido na forma do sentimento religioso, o que se observa, por exemplo, na versão cristã da tradição judaica, quando a noção grega de ágape ( $\alpha \gamma \alpha ́ \pi \eta)$, 'generosidade', é remetida ao divino, como característica dele, restando aos seres humanos, incapazes de amar em razão de uma maldade contingente, apenas ter esse sentimento elevado como uma meta ou um parâmetro, por definição inatingível. Tal é a primeira crítica moderna da religião, efetivada pelo pensamento iluminista. Nesse diapasão,

(...) basta-nos inverter [umkehen] as relações religiosas, tomar [fassen] sempre como fim (Zweck) o que a religião põe como meio, elevar a coisa principal [Hauptsache], a causa, o que para é ela o subordinado, o acessório [Nebensache], a condição, e teremos, destruído então a ilusão [Illusion], frente a nossos olhos a luz desanuviada [ungetrübte] da verdade (FEUERBACH, 1841, p. 376).

Como resultante dos pensamentos desenvolvidos em 1830, ainda como crítica interna da teologia, num esforço de "teologia" laica, mediada pela lógica, dentro do qual o gênero humano emerge como o substitutivo real da fantástica existência do deus pessoal. Correspondente infinito necessário da finitude individual, na qual esta última ganha seus contornos de universalidade.

A importância do tema da generidade como existência objetiva da universalidade humana em sua relação com o nível da particularidade para a tradição filosófica posterior a Feuerbach é por demais conhecido e é atestada pela sumária discussão do pensamento sartreano mais acima desenvolvida. No entanto, com a recente retomada do pensamento neohegeliano no ambiente da pesquisa filosófica acadêmica e sua possível reverberação ideológica, a revisitação da problemática das ressonâncias feuerbachianas como herança ao futuro parece cada vez mais necessária. Não obstante os limites da propositura deste trabalho, conquanto se dê a investigação do pensamento de Feuerbach subsumida à proposta geral de pesquisa em torno de uma bioética materialista, tendo por base a elaboração marxiana, parece pertinente, à guisa de conclusão, a revisitação do tema das "heranças feuerbachianas" em Marx.

Afora a importância decisiva da objeção radical feuerbachiana ao caráter idealista do pensamento de Hegel, a reivindicação do ser efetivo, sensível, para a elaboração da crítica

\begin{tabular}{|c|c|c|c|c|}
\hline Gevista Dialectus & Ano 2 & n. 6 & Janeiro - Agosto 2015 & p. $107-123$ \\
\hline
\end{tabular}


marxiana da especulação hegeliana, destaca-se também a questão acerca da determinação categorial do gênero. O que se exprime por meio desta discussão no fim das contas é a resolução ontológica do estatuto da generidade humana, do caráter próprio do humano que delimita a forma dos indivíduos frente àquelas dos exemplares das espécies animais. A este respeito, vale aqui visitar uma missiva de Marx endereçada a Feuerbach em 11 de agosto de 1844, redigida em Paris, datando, portanto da época dos famosos Manuscritos EconômicoFilosóficos de 1844.Para uma certa leituraainda dominante na tradição interpretativa dos textos marxianos, este juntado de estudos e reflexões sobre os autores da economia política e da filosofia idealista ainda estaria eivado de influências feuerbachianas. Segundo esta linha de interpretação, o período no qual Marx empreende sua primeira aproximação da NationalEconomy clássica as formulações de Feuerbach desempenhariam um papel determinante do ponto de vista filosófico, não somente no que tange ao afastamento da especulação, mas igualmente quanto ao conteúdo de certas categorias, como a de gênero humano.

Entretanto, o que se pode observar do exame da carta em questão é que, por um lado, muito embora haja da parte de Marx o reconhecimento do papel decisivo de Feuerbach para a renovação da filosofia e a recusa dos modos especulativos, por outro lado, o entendimento do que seja gênero humano começa a diferenciar-se daquele feuerbachiano. Entre os elogios generosos e abertos feitos a Feuerbach, como por exemplo, a declaração de que a filosofia do futuro"(...) havia dado - não sei se intencionalmente ou não - em seus escritos um fundamento filosófico ao Socialismo[demSozialismuseinephilosophischeGrundlagegegeben], e os comunistas por sua parte compreenderam este trabalho também neste sentido" (MARX, 1963 P. 425). No transcorrer da carta, além de dar ciência a Feuerbach do andamento das traduções da sua obra em língua francesa, faz questão de assinalar o que considera frágil nas posições dos demais neo-hegelianos, de Bruno Bauer a Stirner. Em especial, é de notar-se o modo como Marx desdenha e acentua o talhe irresolutivo da Crítica como a exercitava Bauer porquanto este defenda uma versão da filosofia que propõe abster-se e até mesmo afastar-se dos sofrimentos e das alegrias da sociedade. O que já deixa entrever o sentido da oposição entre o sábio e a massa que o antigo mestre de Marx desenvolve e para a qual o texto de $A$ sagrada família consagrará uma fina e ácida censura filosófica.

O que importa aqui é situar, não obstante reconhecendo o seu caráter sumário, a distinção que o pensamento marxiano já nesta quadra histórica demonstra haver para com o de Feuerbach. E isto, independentemente de se para Marx esta diferenciação era plenamente

\begin{tabular}{|l|l|l|l|l|}
\hline Q Ponista Dialectus & Ano 2 & n. 6 & Janeiro - Agosto 2015 & p. 107-123 \\
\hline
\end{tabular}


consciente ou ao menos percebida como tal. No mesmo parágrafo onde se reconhece o mérito político-social e as implicações da Philosophie der Zukunft para os movimentos sociais, é possível verificar a emergência da diferença específica do pensamento marxiano, a partir do trecho que se segue, no qual define seu entendimento de gênero humano: "A unidade dos homens com os homens, que está fundada sobre a diferença real dos homens, o conceito de gênero humano trazido do céu da abstração à terra efetiva, que outro é senão o conceito de sociedade!" (MARX, 1963, p. 425)². Os termos não poderiam ser mais explícitos, pelo menos em 1844, quando se inicia a consolidação da passagem das posições típicas do idealismo ativo, que não é apenas uma perspectiva política, mas antes de tudo propriamente ontológica, em direção a uma elaboração teórica materialista sobre a sociabilidade. Porém, de que materialismo se trataria? Reverberaria, em alguma proporção, o naturalismo pressuposto na formulação do entendimento antiespeculativofeuerbachiano ou dafilosofia do futuro?

Evidentemente, amais de um ano das Ad Feuerbach, não temos ainda de maneira explícita as noções de atividade sensível e de humanidade social ou sociedade humana ${ }^{3}$. No entanto, é claramente verificável que a posição marxiana se distingue já da de Feuerbach, porquanto a relacionalidade humana não tem sua matriz definida pela interação $e u$ e tu ou pelo encontro mediado pela afetividade naturalmente compreendida. O que dá o tom é a multiplicidade de liames, de nexos de interdependência factual fundada na variedade de modos de ser dos indivíduos socialmente interconectados. A sociedade supera aqui virtualmente, senão realmente, a amizade como forma própria da generidade dos homens. À fenomenologia das manifestações afectivas dos indivíduos se substitui a percepção reflexiva da rede de relações recíprocas e multilaterais que perfazem a efetiva unidade dos homens com os homens. O gênero humano encontra sua tradução real, seu reino terreno, na vivência societária dos indivíduos, fundada na sua multifacetada existência concreta a qual estimula por feedback o aprofundamento das diferenciações. Assim, posto como conjunto complexo de interações e carecimentos mútuos dos homens, a generidade humana se diferencia pela raiz da forma do gênero naturalmente dado. Os indivíduos não se subsumem à totalidade humana, mas a realizam em franca contradição produtiva com a necessária universalidade vigente como um determinado modo de vida social. Esta "intuição" conceitual primacial empuxará o

\footnotetext{
${ }^{2}$ Die Einheit der Menschen mit den Menschen, die auf dem realen Unterschied der Menschen begründet ist, der Begriff der Menschengattung aus dem Himmel der Abstraktion auf die wirkliche Erde herabgezogen, was ist er anders als der Begriff der Gesellschaft!

${ }^{3}$ Cf. Marx, K. Thesen über Feuerbach, In Marx-Engels Werke, Band 3. Berlin: Dietz Verlag, 1978, p. 533-535.
}

\begin{tabular}{|l|l|l|l|l|}
\hline Revista Dialectus & Ano 2 & n. 6 & Janeiro - Agosto 2015 & p. 107-123 \\
\hline
\end{tabular}


pensamento de Marx progressivamente para além das paragens naturalistas ao caminho do deciframento da anatomia da sociedade civil e da crítica ontológica da economia política.

Referências Bibliográficas:

ALCKMIN, Rodrigo, M. Feuerbach e Marx: da sensibilidade à atividade sensível, Dissertação de Mestrado,

ALVES, Antônio, J. L.; SILVA, Sabina, M. O problema da generidade humana no pensamento de Marx: do gênero à sociabilidade, In Princípios - Revista de Filosofia, volume 19, número 31, Natal, Janeiro/Junho de 2012, p. 235-260.

CHASIN, José. Marx: estatuto ontológico e resolução metodológica. São Paulo: Editorial Boitempo, 2009.

FEUERBACH, Ludwig. A essência do cristianismo. Lisboa/Porto: Fundação CalousteGulbenkian, 1994.

. Gedanken über den Tod und Unsterblichkeit, In Ludwig Feuerbach's sämmtliche Werke, erster Band. Stuttgart: FrommannVerlag, 1960.

AlianzaEditorial, 1993. Pensamientos sobre muerte e immortalidad. Madrid:

Princípios da filosofia do futuro. Covilhã: LusoSofia Press, 2008.

.Das Wesen des Christentums. Leipzig: Verlag von Otto Wigand,

1841.

MARX, Karl. Carta de Carlos Marx a Ludwig Feuerbach, In Cadernos de Paris [notas de lectura de 1844]. Ciudad de Mexico: Ediciones Era, 1980, p. 179-183.

. Die deutsche Ideologie - Kritik der neuesten deutschen Philosophie in

ihren Repräsentanten Feuerbach, B. Bauer und Stirner, und des deutschen Sozialismus in seinen verschiedenen Propheten, In In Marx-Engels Werke, Band 3. Berlin: Dietz Verlag, 1978.

.Marx an Ludwig Feuerbach in Bruckberg, In Marx-Engels Werke, Band 27. Berlin: Dietz Verlag, 1963, p. 425-428.

. Thesen über Feuerbach, In Marx-Engels Werke, Band 3. Berlin: DietzVerlag, 1978, p. 533-535.

MONTAIGNE, Michel de. De como filosofar é aprender a morrer, In Ensaios, Livro I, capítulo X, Coleção Os Pensadores, volume Montaigne. São Paulo: Abril Cultural, 1984, p. 44-51.

SARTRE, Jean-Paul. O ser e o nada - ensaio de ontologia fenomenológica. Petrópolis: Vozes, 2007.

\begin{tabular}{|l|l|l|l|l|}
\hline Q Ponista Dialectus & Ano 2 & n. 6 & Janeiro - Agosto 2015 & p. 107-123 \\
\hline
\end{tabular}

